A EUROPEAN JOURNAL

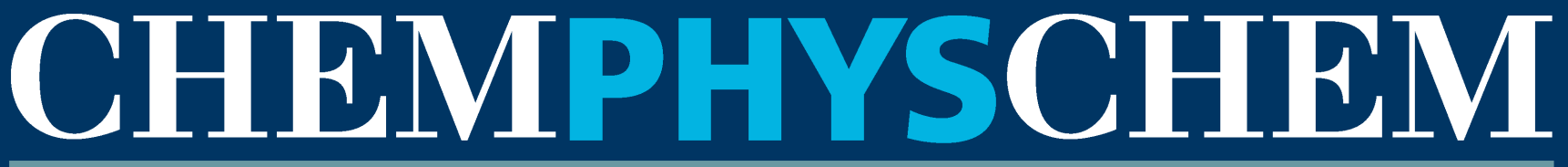

\title{
OF CHEMICAL PHYSICS AND PHYSICAL CHEMISTRY
}

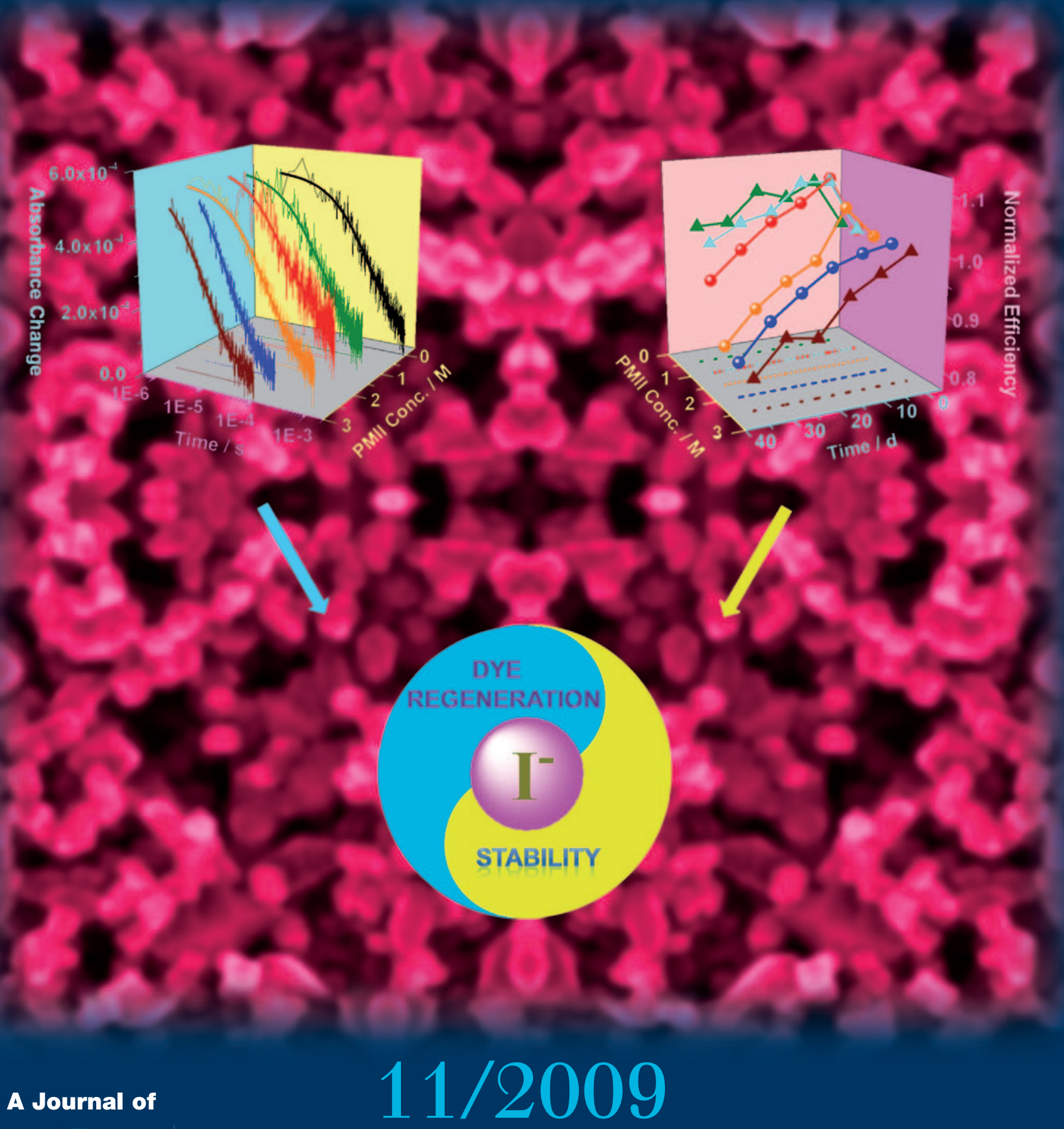

The inside cover picture illustrates the relation between the kinetics of dye regeneration and stability of dye-sensitized solar cells measured at different iodide concentrations in the electrolyte. On page 1834, M. Grätzel et al. present a comprehensive study where devices containing $1.0 \mathrm{M}$ PMII electrolyte show excellent stability during long-time thermal aging in the dark at $80{ }^{\circ} \mathrm{C}$ and under light soaking at $60{ }^{\circ} \mathrm{C}$. 
Inside Cover

Zhipan Zhang, Seigo Ito, Jacques-E. Moser, Shaik M. Zakeeruddin, and Michael Grätzel*

The inside cover picture illustrates the relation between the kinetics of dye regeneration and stability of dye-sensitized solar cells measured at different iodide concentrations in the electrolyte. On page 1834, M. Grätzel et al. present a comprehensive study where devices containing $1.0 \mathrm{M}$ PMII electrolyte show excellent stability during long-time thermal aging in the dark at $80{ }^{\circ} \mathrm{C}$ and under light soaking at $60^{\circ} \mathrm{C}$.

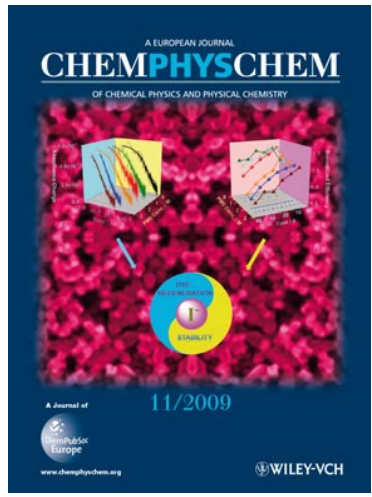




\title{
Influence of lodide Concentration on the Efficiency and Stability of Dye-Sensitized Solar Cell Containing Non-Volatile Electrolyte
}

\author{
Zhipan Zhang, Seigo Ito, Jacques-E. Moser, Shaik M. Zakeeruddin, and Michael Grätzel*[a]
}

Dye-sensitized solar cells based on nanocrystalline $\mathrm{TiO}_{2}$ have been fabricated with an amphiphilic ruthenium sensitizer $\mathrm{NaRu}(4$-carboxylic acid-4'-carboxylate)(4,4'-dinonyl-2,2'-bipyridine)(NCS)2, coded as Z-907Na, and a series of non-volatile 3-methoxyproprionitrile (MPN)-based electrolytes with different concentration of 1-methyl-3-propylimidazolium iodide (PMII).
The short-circuit photocurrent density increases with increasing iodide concentration until at $1.5 \mathrm{M}$ practically quantitative dye regeneration is achieved as proved by time-resolved laser experiments. Devices containing $1.0 \mathrm{M}$ PMII electrolyte show excellent stability during long-time thermal aging at $80^{\circ} \mathrm{C}$ and under light soaking at $60^{\circ} \mathrm{C}$.

\section{Introduction}

Due to its low fabrication costs, environmentally friendly manufacturing materials and remarkably high power conversion efficiency, the dye-sensitized solar cell (DSC) has been attracting increasing scientific and industrial interests ever since its inception in 1991. ${ }^{[1]}$ The DSC comprises a dye-sensitized nanocrystalline porous $\mathrm{TiO}_{2}$, impregnated by a hole transporting material, such as a liquid electrolyte containing the iodide/triiodide $\left(\mathrm{I}^{-} / \mathrm{I}_{3}{ }^{-}\right)$redox couple. Under illumination, fast electron injection takes place from the photoexcited dye molecules into the conduction band of the oxide semiconductor, followed by dye regeneration and hole transport to the counter electrode. The injected electrons diffuse through the oxide film to the current collector and pass subsequently via the external circuit to the counter electrode, where the reduction of the hole carrier, for example, triiodide ions, completes the cycle of events effecting electric power generation from sunlight. ${ }^{[2,3]}$ Record efficiency cells using the ruthenium complexes sensitizer and a volatile electrolyte have achieved a conversion efficiency of over $11 \%$ following optimization of the electrolyte and the mesoscopic structure of the $\mathrm{TiO}_{2}$ electrode. ${ }^{[4,5]}$ However, for its widespread practical use, it is necessary to prevent solvent evaporation and maintain device stability during long-term thermal stress to ascertain 20 years operation under natural conditions.

The advantage of using an amphiphilic polypyridyl ruthenium sensitizer such as Z-907 for maintaining the DSC device stability was first demonstrated in 2003. Subsequently Z-907 was widely used with a non-volatile, lithium-free 3-methoxyproprionitrile (MPN)-based electrolytes. ${ }^{[6-10]}$ Compared to acetonitrile, these non-volatile electrolytes showed a somewhat lower but more stable conversion efficiency under prolonged thermal stress at elevated temperatures. In this report, a series of MPN-based electrolytes are prepared with different concentrations of PMII and its influence on the photovoltaic performance and stability of the DSC is studied.

\section{Results and Discussion}

The recombination of injected electrons with the oxidized sensitizer is a loss channel, which reduces the photocurrent of the cell. Hence, to avoid this electron loss, sufficiently fast regeneration of the dye cation by iodide is needed. A series of electrolytes with different iodide concentration from 0.5 to $2.5 \mathrm{M}$ are employed in the experiments. The limiting anodic current of the electrolyte is measured with ultra-microelectrode technique. The apparent diffusion coefficient $D_{\text {app }}$ of iodide is calculated from the anodic steady-state currents $\left(I_{s s}\right)$ using $I_{s s}=$ $4 n c a F D_{\text {app }}$, where $n=2$ is the number of electrons transferred during iodide oxidation, $F$ is the Faraday constant, $a$ is the radius of the ultra-microelectrode, and $c$ is the bulk concentration of electroactive species. ${ }^{[12]} D_{\text {app }}$ values are presented in Figure 1 as a function of PMII concentration keeping a constant iodine concentration of $0.15 \mathrm{M}$ in all the electrolytes. Within the range of PMII concentrations from 0.5 to $2.5 \mathrm{M}, I_{\mathrm{ss}}$ increases from 229 to $817 \mathrm{nA}$, while $D_{\text {app }}$ decreases from $5.53 \times$ $10^{-6}$ to $4.17 \times 10^{-6} \mathrm{~cm}^{2} \mathrm{~s}^{-1}$. Diffusion by a physical and bond exchange (Grotthuss) mechanism has been proposed to occur in electrolytes containing the $\mathrm{I}^{-} / \mathrm{I}_{3}^{-}$redox couple. ${ }^{[13]}$ When both simple physical diffusion and exchange reaction are present, $D_{\text {app }}$ can be rationalized by the Dahms-Ruff Equation (1)::14-18]

$D_{\text {app }}=D_{\text {phys }}+D_{\text {ex }}=D_{\text {phys }}+k_{\text {ex }} \delta^{2} c / 6$

where $D_{\text {phys }}$ is the physical diffusion coefficient, $k_{\text {ex }}$ is the exchange-reaction rate constant, and $c$ and $\delta$ are the concentration and center-to-center distance between the redox species

[a] Dr. Z. Zhang, Prof. S. Ito, Prof. J.-E. Moser, Dr. S. M. Zakeeruddin, Prof. M. Grätzel

Laboratory for Photonics and Interfaces

Institute of Chemical Sciences and Engineering

Ecole Polytechnique Fédérale de Lausanne

1015 Lausanne (Switzerland)

Fax: $(+41) 216936100$

E-mail:michael.graetzel@epfl.ch 


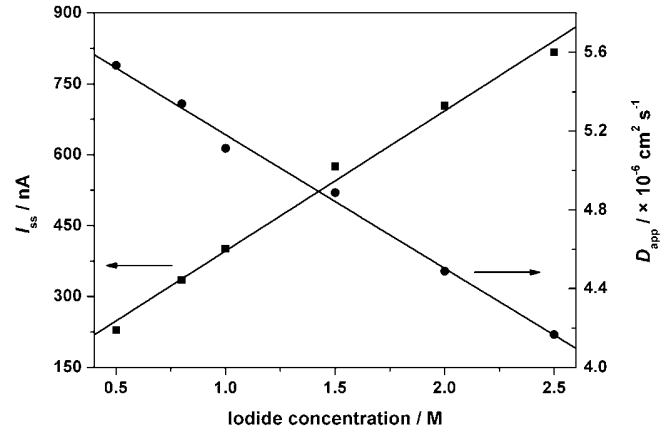

Figure 1. Dependence of steady-state current (square) and iodide diffusion coefficient (dot) on the concentration of PMII in the electrolyte.

participating in the exchange reaction. The observed linear decrease of $D_{\text {app }}$ is due to an increase in the viscosity of the electrolyte with iodide concentration. This indicates that the viscosity-dependent $D_{\text {phys }}$ term dominates over $D_{\text {ex }}$. The latter contribution is small due to the low ratio of $\mathrm{I}_{3}{ }^{-} / \mathrm{I}^{-}$, that is, the large excess of iodide in the electrolyte. Wanatabe et al. investigated Grotthuss transport in $\mathrm{I}^{-} / \mathrm{I}_{3}^{-}$containing ionic liquid system and their results confirmed that the contribution of $D_{\text {ex }}$ to $D_{\text {app }}$ at high iodide/triiodide concentration ratios in the electrolyte is negligible ${ }^{[19,20]}$ in agreement with our results.

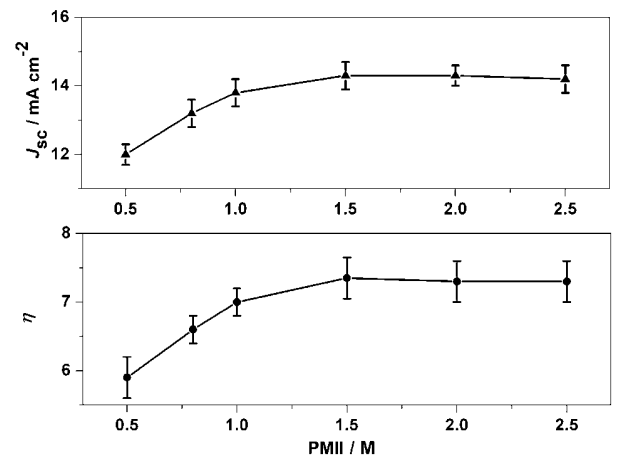

Figure 2. Dependence of photocurrent density and power conversion efficiency of devices under AM 1.5 full sunlight $\left(100 \mathrm{~mW} \mathrm{~cm}^{-2}\right)$ on the concentration of PMII. The iodine concentration is kept at $0.15 \mathrm{M}$.

Table 1 lists the complete set of photovoltaic parameters obtained with these electrolytes under illumination with AM 1.5 sunlight $\left(100 \mathrm{~mW} \mathrm{~cm}^{-2}\right)$. The short-circuit current densities $\left(J_{\mathrm{sc}}\right)$

Table 1. The complete set of photovoltaic parameters for DSCs based on Z907 sensitizer and different electrolytes with various PMII concentrations measured under AM 1.5 full sunlight $\left(100 \mathrm{~mW} \mathrm{~cm}^{-2}\right)$.

\begin{tabular}{|lllll|} 
PMIl conc. [M] & $J_{\text {sc }}\left[\mathrm{mA} \mathrm{cm}^{-}\right]^{2}$ & $V_{\text {oc }}[\mathrm{mV}]$ & $F F$ & $\eta[\%]$ \\
\hline 0.5 & $12.0 \pm 0.3$ & $720 \pm 10$ & $0.66 \pm 0.03$ & $5.9 \pm 0.3$ \\
0.8 & $13.2 \pm 0.4$ & $745 \pm 10$ & $0.65 \pm 0.02$ & $6.6 \pm 0.2$ \\
1.0 & $13.8 \pm 0.4$ & $735 \pm 15$ & $0.67 \pm 0.03$ & $7.0 \pm 0.2$ \\
1.5 & $14.3 \pm 0.4$ & $735 \pm 10$ & $0.68 \pm 0.02$ & $7.4 \pm 0.3$ \\
2.0 & $14.3 \pm 0.3$ & $735 \pm 10$ & $0.69 \pm 0.02$ & $7.3 \pm 0.3$ \\
2.5 & $14.2 \pm 0.4$ & $740 \pm 10$ & $0.69 \pm 0.02$ & $7.3 \pm 0.3$ \\
\hline
\end{tabular}

for PMll concentrations of $0.5,0.8,1.5 \mathrm{M}$, are $12.0,13.2$ and $14.3 \mathrm{~mA} \mathrm{~cm}^{-2}$, respectively. The corresponding conversion efficiencies are $5.9 \%, 6.6 \%$ and $7.4 \%$, respectively, following the trend observed in $J_{\mathrm{sc}}$. Both $J_{\mathrm{sc}}$ and $\eta$ reach a plateau at a PMII concentration of $1.5 \mathrm{M}$. Interestingly, the open-circuit voltage $\left(V_{\text {oc }}\right)$ increases from 720 to $740 \mathrm{mV}$ over this concentration range, which runs counter to thermodynamic expectations, indicating that the $V_{\text {oc }}$ is kinetically controlled by the dark current at the working electrode. This dominates over the decrease in the potential of the counter electrode, which according to the Nernst equation amounts to $62 \mathrm{mV}$ for the five-fold increase in iodide concentration, neglecting changes in the activity coefficients of the electroactive species.

Laser transient absorbance measurements were performed to scrutinize the dynamics of the recombination of the electrons injected in the conduction band of $\mathrm{TiO}_{2}\left(e_{\mathrm{cb}}^{-}\right)$with the oxidized dye $\left(\mathrm{S}^{+}\right)$and that of the dye regeneration reaction with iodide. The kinetic competition between these two chargetransfer processes [Equations (3) and (4)] determines the photon-to-current conversion efficiency (IPCE) of the device, along with the yield for light harvesting, electron injection and charge carrier collection. Figure 3 displays the temporal evolu-

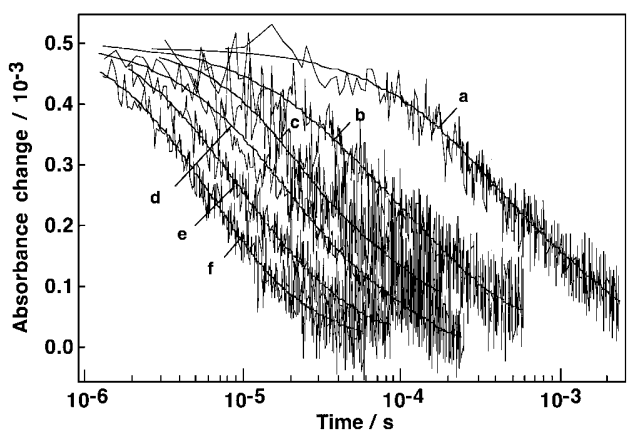

Figure 3. Transient absorbance decay kinetics of the oxidized state of Z907Na dye adsorbed on nanocrystalline $\mathrm{TiO}_{2}$ films in pure MPN solvent (a), and in the presence of electrolytes of increasing PMII concentration: $0.5 \mathrm{M}$ (b), $0.8 \mathrm{M}$ (c), $1.5 \mathrm{M}$ (d), $2.0 \mathrm{M}$ (e), and $2.5 \mathrm{M}$ (f). Absorbance changes were measured at a probe wavelength of $680 \mathrm{~nm}$, employing $600 \mathrm{~nm}$ pulsed laser excitation ( $5 \mathrm{~ns}$ fwhm pulse duration, $25 \mu \mathrm{J} \mathrm{cm}^{-2}$ pulse fluence). Solid lines drawn on top of experimental data are double exponential fits of the transient decays.

tion of the absorbance measured at $\lambda=680 \mathrm{~nm}$ of a transparent Z-907Na dye-sensitized $\mathrm{TiO}_{2}$ film upon pulsed laser excitation at $600 \mathrm{~nm}$ (pulse duration $5 \mathrm{~ns}$; pulse fluence, $25 \mu \mathrm{J} \mathrm{cm}^{-2}$ ). Ultrafast electron injection [Eq. (2)] produces the appearance of a positive transient signal recorded at $680 \mathrm{~nm}$, which is mainly due to light absorption by the oxidized sensitizer $\left(\mathrm{S}^{+}\right)$. In the absence of iodide donor (trace a), this signal decays as a consequence of recapture of the conduction band electron by the oxidized dye [Eq. (3)]:

$$
\begin{aligned}
& \mathrm{S}^{*}\left|\mathrm{TiO}_{2} \rightarrow \mathrm{S}^{+}\right| \mathrm{TiO}_{2}+e_{\mathrm{cb}}^{-}\left(\mathrm{TiO}_{2}\right) \\
& \mathrm{S}^{+}\left|\mathrm{TiO}_{2}+e_{\mathrm{cb}}^{-}\left(\mathrm{TiO}_{2}\right) \rightarrow \mathrm{S}\right| \mathrm{TiO}_{2} \\
& \mathrm{~S}^{+}\left|\mathrm{TiO}_{2}+2 \mathrm{I}^{-} \rightarrow \mathrm{S}\right| \mathrm{TiO}_{2}+\mathrm{I}_{2}^{-}
\end{aligned}
$$


The recorded kinetics reported in Figure 3 could not be fitted by a simple first-order law. Hence half reaction times $\left(t_{1 / 2}\right)$ were extracted to quantify the process. Average pseudofirst-order rate constants $k_{r}^{\prime}=1 / t_{1 / 2}$ are computed from these data and yields $\left(\eta_{\text {reg }}\right)$ for the dye regeneration are calculated using the simple relation in Equation (5):

$\eta_{\text {reg }}=k_{\mathrm{r}}^{\prime} /\left(k_{\mathrm{r}}^{\prime}+k_{\mathrm{b}}\right)$

where $k_{\mathrm{b}}$ is the reciprocal of the half-life time of $\mathrm{S}^{+}$measured in the absence of iodide. Figure 3 trace a, displays the kinetics of the $\mathrm{S}^{+}$transient absorbance decay through charge recombination in pure MPN, showing a typical $t_{1 / 2}$ of about $400 \mu \mathrm{s}$. In the presence of $0.5 \mathrm{M}$ iodide (trace $\mathrm{b}$ ), the decay of the oxidized dye signal is accelerated to $t_{1 / 2} \sim 80 \mu$ s due to the dye regeneration by the mediator [Eq. (4)] intercepting the back-electron transfer. The half-life time shortens to $t_{1 / 2} \sim 30 \mu$ for a PMIl concentration of $0.8 \mathrm{M}$ (trace $\mathrm{c}$ ). By the definition of Equation (5), the yield of dye regeneration $\eta_{\text {reg }}$ is calculated to be $83 \%$ and $93 \%$ at 0.5 and $0.8 \mathrm{M}$ PMII, respectively, in keeping with the results obtained previously using a similar system. ${ }^{[6]}$ This limits the incident photon to current conversion efficiency and hence the photocurrent density delivered by solar cells using these two electrolytes. Increasing the PMII concentration beyond $0.8 \mathrm{M}$ expedites further the interception of charge recombination. Thus at $1.5 \mathrm{M}$ PMII (trace d), $\mathrm{S}^{+}$decays with $t_{1 / 2}$ $\sim 20 \mu$ s increasing the yield of interception to 95 percent. Further increase in iodide concentration to 2.0 and $2.5 \mathrm{M}$ gives $t_{1 / 2}$ values of $10 \mu \mathrm{s}$ and $7 \mu$ s (traces e and f), respectively. The corresponding augmentation of the yield of dye regeneration from to $97 \%$ and $98 \%$ is not reflected in the short circuit photocurrent values, which remains constant at the higher iodide concentration (Figure 2) and the predicted small additional increase being probably within the error limit of the measurements.

Figure 4 plots the change of the reciprocal half reaction time $1 / t_{1 / 2}$ versus the concentration of iodide in the electrolyte. The obtained concentration dependence is not linear for $0<$ $\left[\mathrm{I}^{-}\right]<1.5 \mathrm{M}$, showing that the dye regeneration kinetics cannot be simply approximated by a pseudo first order rate law at

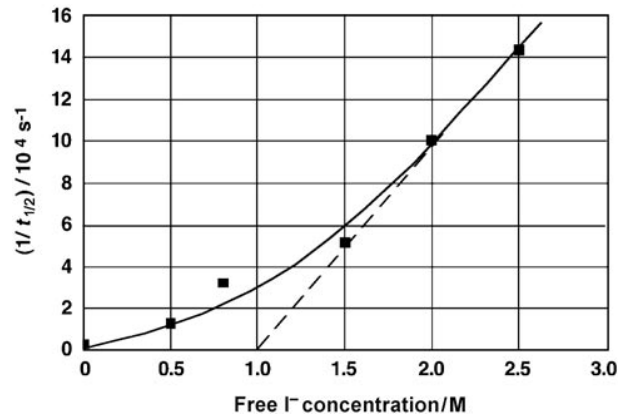

Figure 4. Dependence of the first order rate constant $k_{r}^{\prime}=1 / t_{1 / 2}$ of the interception of the oxidized dye by iodide upon the concentration of free $\mathrm{I}^{-}$in the studied series of electrolytes. Data points are extracted from the decay kinetics of Figure 3. The dashed straight line has a slope of $1 \times 10^{5} \mathrm{M}^{-1} \mathrm{~s}^{-1}$, while the solid curve is only for visualization. lower concentrations. The slope of the function $1 / t_{1 / 2}=f\left(\left[\mathrm{I}^{-}\right]\right)$ increases from a value of $2 \times 10^{4} \mathrm{M}^{-1} \mathrm{~s}^{-1}$ for $\left[\mathrm{I}^{-}\right] \leq 0.5 \mathrm{M}$ to approximately $1 \times 10^{5} \mathrm{M}^{-1} \mathrm{~s}^{-1}$ for $\left[\mathrm{I}^{-}\right] \geq 2 \mathrm{M}$. As the iodide concentration exceeds $1.5 \mathrm{M}$, the slope stays rather invariable, thus yielding a second-order rate constant $k_{r}^{\prime \prime} \approx 1 \times 10^{5} \mathrm{M}^{-1} \mathrm{~s}^{-1}$. This value is comparable with that obtained for PMII/EMIDCN binary ionic liquids associated with the same Z-907 dye sensitizer, ${ }^{[21]}$ where a second-order rate constant $k_{\mathrm{r}}{ }^{\prime \prime}=\left(t_{1 / 2}\left[\mathrm{I}^{-}\right]\right)^{-1}$ $\approx 10^{5} \mathrm{M}^{-1} \mathrm{~s}^{-1}$ can be roughly estimated for the interception reaction. The observed sublinear function for $\left[\mathrm{I}^{-}\right]<1.5 \mathrm{M}$ in Figure 4 indicates that a kinetic salt effect is operative, that is, the apparent concentration of iodide reacting with the $\mathrm{S}^{+}$species is smaller than the bulk concentration of the electrolyte. This suggests that a repulsive interaction exists between - $^{-}$ anions and the dyed surface. In addition the two nonyl-chains of the Z-907 hinder sterically the access of iodide to the reactive site of the oxidized sensitizer molecule. A much higher value of the second-order rate constant $k_{\mathrm{r}}^{\prime \prime} \approx 2 \times 10^{7} \mathrm{M}^{-1} \mathrm{~s}^{-1}$ was observed for systems associating Lil electrolytes and [cis$\left.\mathrm{Ru}^{\prime \prime}\left(2,2^{\prime} \text {-bipyridyl-4,4'-dicarboxylate-H }\right)_{2}(\mathrm{NCS})_{2}\right]_{2}-\left(\mathrm{TBA}^{+}\right)_{2} \quad(\mathrm{~N}-719)$ dye sensitizer, whose ligands do not carry any aliphatic chain. ${ }^{[22]}$ It is then quite evident that the two nonyl groups equipping the Z-907 dye oppose a barrier to the approach of iodide anions and cause a decrease of the interception reaction rate constant by 2 orders of magnitude. The use of this particular dye, which was found otherwise to be very beneficial to the stability of the solar cell, then implies that high iodide concentrations are required to allow for the efficient interception of the back-electron transfer from the photoinjected electrons to the oxidized sensitizer, $\mathrm{S}^{+}$.

Accelerated thermal stability tests were performed with carefully sealed devices. Cells were fabricated using electrolytes comprising 1.0, 1.5, and $2.5 \mathrm{M}$ PMII and stored in the oven at $80^{\circ} \mathrm{C}$ for 1000 hour exposure. Results shown in Figure 5 reveal that devices based on $1.0 \mathrm{M}$ PMII show superior stability to the others, less than $10 \%$ decrease in short-circuit photocurrent density and photovoltaic conversion efficiency being witnessed during 35 days of aging at $80^{\circ} \mathrm{C}$. The 1.5 and $2 \mathrm{M}$ PMII electrolytes are less stable, showing a $\sim 15 \%$ decrease in efficiency

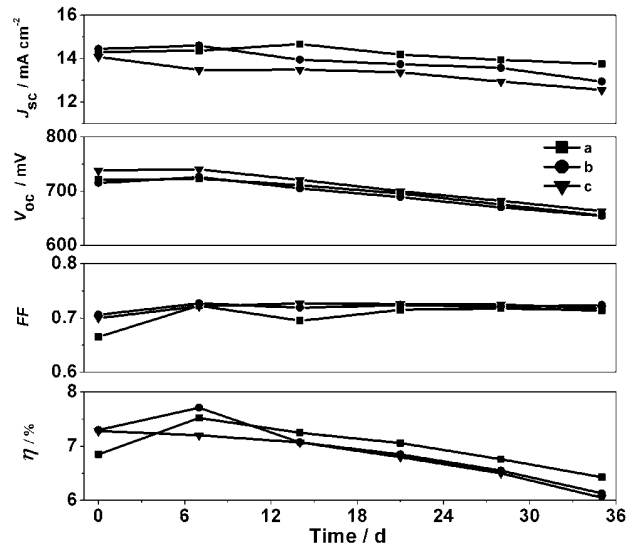

Figure 5. Temporal evolution of normalized photovoltaic parameters of devices fabricated with electrolytes containing a) 1.0, b) 1.5 , c) $2.0 \mathrm{M}$ PMII during successive thermal aging at $80^{\circ} \mathrm{C}$. 
during the same time. Preliminary results appear to corroborate that a higher iodide concentration is detrimental to thermal stability probably due to dye replacement at the surface by $\mathrm{I}^{-}$at the high salt levels as indicated by the continuous drop in short-circuit photocurrent density of devices with $2.0 \mathrm{M}$ PMII containing electrolytes.

To examine the photo-stability of the cells, they were subjected to long term light soaking in a solar simulator at full intensity raising the device temperature to $60^{\circ} \mathrm{C}$ light. Results illustrating the time evolution of the photovoltaic parameters are shown in Figure 6. For devices containing 0.5 and $1.0 \mathrm{M}$

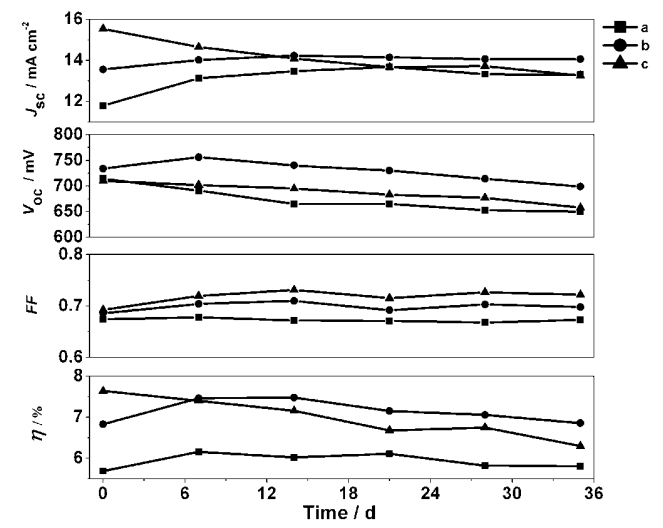

Figure 6. Temporal evolution of photovoltaic parameters of devices fabricated with electrolytes containing a) 0.5, b) 1.0 , c) $2.5 \mathrm{M}$ PMII under the light soaking condition at $60^{\circ} \mathrm{C}$.

PMII, a slight drop in $V_{\text {oc }}$ was compensated by an increase in $J_{\text {sc. }}$. The overall performance of the cells had barely changed after 5 weeks of aging. On the other hand, the efficiency of the device with $2.5 \mathrm{M}$ PMII decreased notably, due to the loss in $V_{\text {oc }}$ and a lack of mitigation by $J_{\text {sc }}$.

\section{Conclusions}

In summary, with the aid of microelectrode, steady-state current of a series of non-volatile electrolytes with different PMII concentrations was measured and the apparent diffusion coefficient was found to decrease linearly with the increase of PMII concentration. Laser flash results demonstrated that PMII concentrations lower than $1 \mathrm{M}$ are responsible for incomplete dye regeneration. Additionally, further increase in iodide concentration became kinetically redundant for charge recombination between oxidized dye sensitizer and electron in the conduction band of $\mathrm{TiO}_{2}$. Devices show excellent long-term stability during light soaking at $60^{\circ} \mathrm{C}$ and thermal aging at $80^{\circ} \mathrm{C}$ with electrolyte composed of $1.0 \mathrm{M}$ PMII.

\section{Experimental Section}

Reagents and Electrolytes: All chemicals and solvents used in the present work were of puriss quality. N-methylbenzimidazole (NMBI) was purchased from Aldrich and recrystallized from diethylether before use. 3-Methoxypropionitrile (MPN) puriss quality was ob- tained from Fluka and distilled before use. NaRu(4-carboxylic acid4'-carboxylate)[4,4'-dinonyl-2,2'-bipyridine] (NCS) $)_{2}$ coded as Z-907Na, and 1-methyl-3-propylimidazolium iodide (PMII) was prepared according to the literature method ${ }^{[6]}$ and its purity confirmed by ${ }^{1} \mathrm{H}$ NMR spectroscopy. $400 \mathrm{~nm}$-sized $\mathrm{TiO}_{2}$ particles were received as a gift from CCIC (Japan). All the electrolytes contained $0.15 \mathrm{M} \mathrm{I}_{2}$, $0.1 \mathrm{M}$ guanidinium thiocyanate, $0.5 \mathrm{M} \mathrm{N}$-methylbenzimidazole and different concentrations of 1-propyl-3-methylimidazolium iodide ranging from $0.5 \mathrm{M}$ to $2.5 \mathrm{M}$ as the iodide source in MPN solvent. As iodine associate readily with $\mathrm{I}^{-}$to form $\mathrm{I}_{3}^{-}$, in all the electrolytes, the concentration of triiodide is $0.15 \mathrm{M}$. Hence, the final concentration of $\mathrm{I}^{-}$in all these electrolytes was in the range of $0.35-2.35 \mathrm{M}$

Spectroscopic Measurements: For photoelectrochemical measurements, a $450 \mathrm{~W}$ xenon light source (Oriel, USA) was used to provide an intensity of $100 \mathrm{~mW} \mathrm{~cm}^{-2}$ (the equivalent of one sun at global AM 1.5) at the surface of the solar cell. The spectral output of the lamp was adjusted in the region of $350-750 \mathrm{~nm}$ with the aid of a Schott K113 Tempax sunlight filter (Präzisions Glas \& Optik $\mathrm{GmbH}$, Germany) so as to reduce the mismatch between the simulated and true solar spectra to less than $2 \%$. Various incident light intensities were regulated with neutral wire mesh attenuators. The current voltage characteristics of the cell under these conditions were obtained by applying an external potential bias to the cell and measuring the generated photocurrent with a Keithley model 2400 digital source meter (Keithley, USA).

Cyclic voltammetry measurements were performed on a computercontrolled Autolab P20 electrochemical workstation (Eco Chimie, Netherlands). A two-electrode electrochemical cell, consisting of a $5.0 \mu \mathrm{m}$ radius Pt ultra-microelectrode as working electrode and a Pt foil as counter electrode, was used for measurements of the iodide diffusion coefficient and iodide flux. Due to the possible liquid junction potential, the used reference electrode was calibrated by measuring the redox potential of ferrocene dissolved in MPN.

Nanosecond Laser Transient Absorbance Measurements: Dye-sensitized, $8 \mu \mathrm{m}$ thick transparent nanocrystalline $\mathrm{TiO}_{2}$ films were irradiated by nanosecond laser pulses produced by a Powerlite 7030 frequency-tripled Q-switched Nd:YAG laser (Continuum, USA) pumping an OPO-355 optical parametric oscillator (GWU, Germany) tuned at $600 \mathrm{~nm}(30 \mathrm{~Hz}$ repetition rate, pulse width at half-height of $5 \mathrm{~ns}$ ). To inject on the average less than one electron per nanocrystalline $\mathrm{TiO}_{2}$ particle, the pulse fluence was attenuated to a maximum of $25 \mu \mathrm{J} \mathrm{cm}^{-2}$ by use of absorptive neutral density filters. The probe light from a Xe arc lamp was passed through an interference filter monochromator, various optical elements, the sample, and a grating monochromator before being detected by a fast photomultiplier tube. Averaging over ca. 2000 laser shots was necessary to obtain satisfactory signal/noise ratios.

Device Fabrication: A double-layer $\mathrm{TiO}_{2}$ mesoscopic film was used as the photoanode. A $10 \mu \mathrm{m}$ thick transparent layer of $20 \mathrm{~nm}$-sized $\mathrm{TiO}_{2}$ particles was first printed on the fluorine-doped $\mathrm{SnO}_{2}$ conducting glass electrode and further coated with a $4 \mu \mathrm{m}$ thick second layer of $400 \mathrm{~nm}$-sized light scattering anatase particles. The details for the preparation of mesoscopic $\mathrm{TiO}_{2}$ film has been described elsewhere. ${ }^{[11]}$ The double-layer structured $\mathrm{TiO}_{2}$ electrode was first sintered at $500^{\circ} \mathrm{C}$ for $20 \mathrm{~min}$ and cooled at ambient temperature down to $80^{\circ} \mathrm{C}$. It was then immersed into the dye solution at room temperature for $12 \mathrm{~h}$ before assembly with a thermally platinized conducting glass counter electrode. The dye solution consisted of $0.3 \mathrm{~mm}$ Z-907Na in acetonitrile and tert-butyl alcohol 
(volume ratio, 1:1). The electrodes were separated by a $35 \mu \mathrm{m}$ thick Bynel hot-melt ring (DuPont, USA) and sealed by heating. The internal space was evacuated and then filled with electrolyte through a filling hole made by a sandblasting drill on the counter electrode glass substrate. Finally, the electrolyte introduction hole was sealed with a Bynel sheet under a thin glass cover by heating to produce the device.

Stability Test: Hermetically sealed cells were used for long term stability tests under visible light soaking $\left(60^{\circ} \mathrm{C}\right)$ and high temperature $\left(80^{\circ} \mathrm{C}\right)$ conditions. For visible light soaking experiment, the cells were covered with a $50 \mu \mathrm{m}$-thick polyester film (Preservation Equipment Ltd, UK) as a UV cutoff filter (below $400 \mathrm{~nm}$ ) and irradiated at open circuit under a Suntest CPS plus lamp (ATLAS GmbH, $100 \mathrm{~mW} \mathrm{~cm}^{-2}, 60^{\circ} \mathrm{C}$ ). Some cells were subjected to more critical, high temperature stability test by putting them in the oven $\left(80^{\circ} \mathrm{C}\right)$ in the darkness. Photoelectrochemical measurements were carried out after the cells were irradiated at open circuit under the above mentioned light soaking condition for $1 \mathrm{~h}$ and allowed to cool and equilibrate at room temperature for another hour.

\section{Acknowledgements}

This work was supported by the Swiss National Science Foundation. We are grateful to Mr. P. Comte for the film fabrication and T. Koyanagi (CCIC, Japan) for a free sample of the $400 \mathrm{~nm}$ sized light scattering anatase particles.

Keywords: dyes/pigments • energy conversion • iodide concentration · semiconductors · stability

[1] B. O'Regan, M. Grätzel, Nature 1991, 353, 737-740.
[2] M. Grätzel, Nature 2001, 414, 338-344.

[3] A. Hagfeldt, M. Grätzel, Chem. Rev. 1995, 95, 49-68.

[4] M. Grätzel, Chem. Lett. 2005, 34, 8-13.

[5] Y. Chiba, A. Islam, Y. Watanabe, R. Komiya, N. Koide, L. Han, Jpn. J. Appl. Phys. Part 2 2006, 45, L638-L640.

[6] P. Wang, S. M. Zakeeruddin, J. E. Moser, M. K. Nazeeruddin, T. Sekiguchi, M. Grätzel, Nat. Mater. 2003, 2, 402-407.

[7] P. Wang, S. M. Zakeeruddin, R. Humphry-Baker, J. E. Moser, M. Grätzel, Adv. Mater. 2003, 15, 2101-2104.

[8] P. Wang, C. Klein, R. Humphry-Baker, S. M. Zakeeruddin, M. Grätzel, J. Am. Chem. Soc. 2005, 127, 808-809.

[9] P. Wang, C. Klein, R. Humphry-Baker, S. M. Zakeeruddin, M. Grätzel, Appl. Phys. Lett. 2005, 86, 123508.

[10] D. B. Kuang, C. Klein, H. J. Snaith, J. E. Moser, R. Humphry-Baker, P. Comte, S. M. Zakeeruddin, M. Grätzel, Nano Lett. 2006, 6, 769-773.

[11] C. J. Barbé, F. Arendse, P. Comte, M. Jirousek, F. Lenzmann, V. Shklover, M. Grätzel, J. Am. Ceram. Soc. 1997, 80, 3157-3171.

[12] A. J. Bard, L. R. Faulkner, Electrochemical Methods: Fundamentals and Applications, 2nd ed., Wiley-VCH, Weinheim, 2001.

[13] W. Kubo, K. Murakoshi, T. Kitamura, S. Yoshida, M. Haruki, K. Hanabusa, H. Shirai, Y. Wada, S. Yanagida, J. Phys. Chem. B 2001, 105, 12809-12815.

[14] H. Dahms, J. Phys. Chem. 1968, 72, 362-364.

[15] I. Ruff, L. Botar, J. Chem. Phys. 1985, 83, 1292-1297.

[16] I. Ruff, V. J. Friedrich, J. Phys. Chem. 1971, 75, 3297-3302.

[17] I. Ruff, V. J. Friedrich, K. Csillag, J. Phys. Chem. 1972, 76, 162-165.

[18] M. Majda in Molecular Design of Electrode Surfaces (Ed.: R. W. Murray), Wiley, New York, 1992, p. 159.

[19] R. Kawano, M. Watanabe, Chem. Commun. 2003, 330-331.

[20] R. Kawano, H. Matsui, C. Matsuyama, A. Sato, M. A. B. H. Susan, N. Tanabe, M. Watanabe, J. Photochem. Photobiol. A 2004, 164, 87-92.

[21] P. Wang, S. M. Zakeeruddin, J. E. Moser, M. Grätzel, J. Phys. Chem. B 2003, 107, 13280-13285.

[22] S. Pelet, J. E. Moser, M. Grätzel, J. Phys. Chem. B 2000, 104, 1791-1795.

Received: March 17, 2009

Published online on May 26, 2009 